\title{
Performance improvement of ionic surfactant flooding in carbonate rock samples by use of nanoparticles
}

\author{
Mohammad Ali Ahmadi ${ }^{1} \cdot$ James Sheng $^{2}$
}

Received: 22 January 2016/Published online: 6 July 2016

(c) The Author(s) 2016. This article is published with open access at Springerlink.com

\begin{abstract}
Various surfactants have been used in upstream petroleum processes like chemical flooding. Ultimately, the performance of these surfactants depends on their ability to reduce the interfacial tension between oil and water. The surfactant concentration in the aqueous solution decreases owing to the loss of the surfactant on the rock surface in the injection process. The main objective of this paper is to inhibit the surfactant loss by means of adding nanoparticles. Sodium dodecyl sulfate and silica nanoparticles were used as ionic surfactant and nanoparticles in our experiments, respectively. AEROSIL ${ }^{\circledR} 816$ and AEROSIL ${ }^{\circledR} 200$ are hydrophobic and hydrophilic nanoparticles. To determine the adsorption loss of the surfactant onto rock samples, a conductivity approach was used. Real carbonate rock samples were used as the solid phase in adsorption experiments. It should be noted that the rock samples were water wet. This paper describes how equilibrium adsorption was investigated by examining adsorption behavior in a system of carbonate sample (solid phase) and surfactant solution (aqueous phase). The initial surfactant and nanoparticle concentrations were 500-5000 and 500-2000 ppm, respectively. The rate of surfactant losses was extremely dependent on the concentration of the surfactant in the system, and the adsorption of the surfactant decreased with an increase in the nanoparticle
\end{abstract}

Mohammad Ali Ahmadi

ahmadi6776@yahoo.com

1 Department of Petroleum Engineering, Ahwaz Faculty of Petroleum Engineering, Petroleum University of Technology, Ahwaz, Iran

2 Petroleum Department, Texas Tech University, P.O. Box 43111, Lubbock, TX 79409, USA

Edited by Yan-Hua Sun concentration. Also, the hydrophilic nanoparticles are more effective than the hydrophobic nanoparticles.

Keywords Adsorption · Hydrophobic silica nanoparticles · Hydrophilic silica nanoparticles · Ionic surfactant .

Carbonate rock

\section{Introduction}

Owing to declining oil production rates around the world, it is important to improve the oil recovery factor (Zang et al. 2008). To obtain more oil from depleted oil fields, various methods called "enhanced oil recovery (EOR)" techniques should be utilized. Enhanced oil recovery approaches have different subsets, including thermal oil recovery, chemical oil recovery, and miscible and immiscible flooding. Chemical flooding has been attracted more attention in recent years, because it has various challenges such as wettability alteration, adsorption loss, interfacial tension reduction, and oil and water phase behavior (Kong and Ohadi 2010; Ahmadi and Shadizadeh 2013a, b, 2015; Ahmadi et al. 2014).

To improve the robustness and effectiveness of water flooding or chemical flooding, nanotechnology approaches have been implemented widely, such as mobility ratio improvement (Shah 2009; Suleimanov et al. 2011), interfacial tension reduction (Le et al. 2011), emulsion stability, wettability alteration (Al-Anssari et al. 2016), and resistance to adsorption onto reservoir rocks (Ahmadi and Shadizadeh 2012, 2013c). Le et al. investigated synergistic mixtures of surfactants and silica nanoparticles for enhanced oil recovery (EOR) in challenging reservoirs such as high-temperature reservoirs. To meet this goal, they carried out various tests including different mixtures 
of silica nanoparticles and surfactants. Their experiments divided into two types: (1) interfacial tension measurement and (2) contact angle measurement. They used a spinning drop tension meter (Temco 500) to investigate the effects of silica nanoparticles on IFT values. Moreover, they investigated the effect of silica nanoparticles on the oil displacement efficiency by contact angle measurements. Owing to their reported outcomes, some of the mixtures revealed appropriate agents for EOR purposes due to their thermal stability at $91{ }^{\circ} \mathrm{C}$ and infinitesimal loss on the rock surface by adsorption (Le et al. 2011). Suleimanov et al. (2011) conducted some experiments into the modification of interfacial properties in aqueous solutions by dispersing nanoparticles in the addressed solutions. They used different nonferrous nanoparticles in their experiments and draw a conclusion that the nanosuspension could increase the efficiency of oil displacement in porous media.

Onyekonwu and Ogolo (2010) investigated the effects of different polysilica nanoparticles (PSNP), on the wettability of reservoir rocks. They utilized water wet core samples and illustrated that silane-treated neutral and hydrophilic polysilica nanoparticles increased the recovery factor by $50 \%$ over primary and secondary recoveries. AlAnssari et al. (2016) studied the ability of silica nanoparticles to change the wettability of calcite rocks, including both oil-wet and mixed-wet calcite samples. They concluded that silica nanoparticles are able to change the wettability of such rocks from oil-wet to mixed/water wet, and this means that this type of nanoparticles is useful for EOR. Moreover, they pointed out that the concentration of nanoparticles and salinity of the solution were the most important factors in changing the wettability of the calcite rock samples. Furthermore, Ju and Fan (2009) demonstrated that untreated polysilica nanoparticles could change the wettability of sandstones from oil wet to water wet by an adsorption phenomenon. In addition, adding untreated polysilica nanoparticles could improve the effective water permeability, while decreasing the absolute permeability of the addressed sandstone samples.

Another characteristic of nanoparticles is the stabilization of droplets of emulsions that are small enough to move through the porous media without much retention (Zhang et al. 2010). The most-implemented fumed silica nanoparticles were spherically shaped, with a diameter of twenty to thirty nanometers. Also, the wettability of fumed silica nanoparticles is changed by coating materials, such as silanol. If silanol groups of the surface coating groups of the silica nanoparticle are greater than $90 \%$, the silica nanoparticle is considered a hydrophilic particle. Owing to this hydrophilic characteristic, silica nanoparticles could form a highly stabilized oil-in-water emulsion. On the other hand, if the coating groups on the surface of the silica nanoparticle are only $10 \%$ silanol groups, the silica nanoparticle is considered hydrophobic and will form a stable water-in-oil emulsion (Zhang et al. 2010). Another property of nanoparticles is their high ability to stabilize oil-in-water emulsions, and the nanoemulsions can travel for a long distance in reservoirs without much retention (Kong and Ohadi 2010). In addition, nanoparticles can stabilize emulsions of supercritical $\mathrm{CO}_{2}$ in water and emulsions of water in supercritical $\mathrm{CO}_{2}$ (Dickson et al. 2004; Adkins et al. 2007).

Kanj et al. (2009) investigated the transport of nanoparticles in porous media and estimated the optimum size of nanoparticles effectively used in reservoir rocks. In addition, Skauge et al. (2010) studied the flow behavior of silica nanoparticles in porous media and found silica nanoparticles could move easily in porous media. Owing to their inherent conditions in reservoirs, they pose no environmental impacts. Due to their very small sizes, they also could not create tension or block pores, which make them an excellent advantage for EOR goals.

The huge potential of nanoparticles in upstream oil and gas is shown by various applications of nanoparticles in different oil and gas processes. Owing to the inherent characteristics of silica nanoparticles, they have been studied in recent years to improve the sweep efficiency of water flooding. Ogolo et al. (2012) studied the effect and potential of a combination of three nanoparticles, including $\mathrm{Al}_{2} \mathrm{O}_{3}, \mathrm{MgO}, \mathrm{Fe}_{2} \mathrm{O}_{3}$, and $\mathrm{SiO}_{2}$ nanoparticles. Some combinations of these nanoparticles were better than silica nanoparticles alone. Hendraningrat et al. (2012) found nanoparticles could decrease the interfacial tension between oil and brine/nanofluid. Also, the nanofluid could increase oil recovery by $13 \%$ for both secondary and tertiary recoveries (Hendraningrat et al. 2012, 2013; Li et al. 2013).

In recent years, Ahmadi and Shadizadeh (2012, 2013c) studied the effect of nanoparticles on the adsorption loss of a surfactant derived from plant leaves on sandstone, shale sandstone, and sandstone mineral samples. Increasing the hydrophobicity of silica nanoparticles resulted in a reduction in adsorption loss of the surfactant (Ahmadi and Shadizadeh 2012, 2013c). This is due to the fact that the increasing hydrophobicity of nanoparticles may enhance hydrophobic bonds between the surfactant head and the hydrophobic part of silica nanoparticles. Consequently, fewer surfactant molecules are available to adsorb onto the rock surface.

The adsorption mechanisms of a combination of silica nanoparticles and sodium dodecyl sulfate on carbonate minerals have not been studied previously. The aim of this paper is to study the adsorption behavior of the mentioned ionic surfactant in the presence of silica nanoparticles in aqueous solutions. Moreover, the effects of silica nanoparticles on the oil sweep efficiency of the ionic 
surfactant in porous media were investigated with a core displacement apparatus. Two different types of silica nanoparticles were utilized in both adsorption and core displacement experiments. The experimental results were explained and discussed in detail.

\section{Materials and methods}

\subsection{Chemicals}

The ionic surfactant used was sodium dodecyl sulfate (SDS), which was identified as a good foaming agent. The ionic surfactant SDS was purchased from the Merck Company with a high degree of purification (99\%). It should be noted that the utilized chemicals were used as received without any further purification.

\subsection{Nanoparticles}

The nanoparticles were made from $\mathrm{SiO}_{2}$ and an additive (Ahmadi and Shadizadeh 2012, 2013c). A transmission electron microscope (TEM) was used to measure the spherical shape and size of the silica nanoparticles as shown in Fig. 1. In order to investigate the effect of nanoparticle wettability on the inhibition of surfactant adsorption loss, two types of silica nanoparticles, hydrophilic and hydrophobic silica nanoparticles, were used. AEROSIL ${ }^{\circledR} 816$ and AEROSIL ${ }^{\circledR} 200$ were used as hydrophobic and hydrophilic nanoparticles which were purchased from Degussa.

AEROSIL $^{\circledR} 816$ is a fumed silica after treated with hexadecylsilane based on AEROSIL ${ }^{\circledR}$ 200. It is used in water-based coating systems. AEROSIL ${ }^{\circledR} 816$ can be applied in coating systems as an antisettling agent, for stabilization of pigments, and to enhance the effect of corrosion protection. It is also effective in controlling the rheology of complex liquid systems.

\subsection{Core and crushed core samples}

A core sample used in core displacement tests was cut from an Iranian carbonate reservoir rock, and its characteristics are illustrated in Table 1. To evaluate adsorption of the ionic surfactant in the presence of different silica nanoparticles, two core samples were crushed using a jaw crusher and then passed through specific sieves (50-70 mesh size) for repeatability of the experiments and to double check our adsorption experiments (Salari et al. 2011; Ahmadi and Shadizadeh 2012, 2013a, b, c, 2015; Ahmadi et al. 2014; Zendehboudi et al. 2013). X-ray diffraction (XRD) was conducted to analyze the phase composition of the core samples, and the results are shown in Fig. 2. As illustrated in Fig. 2, the rock samples were
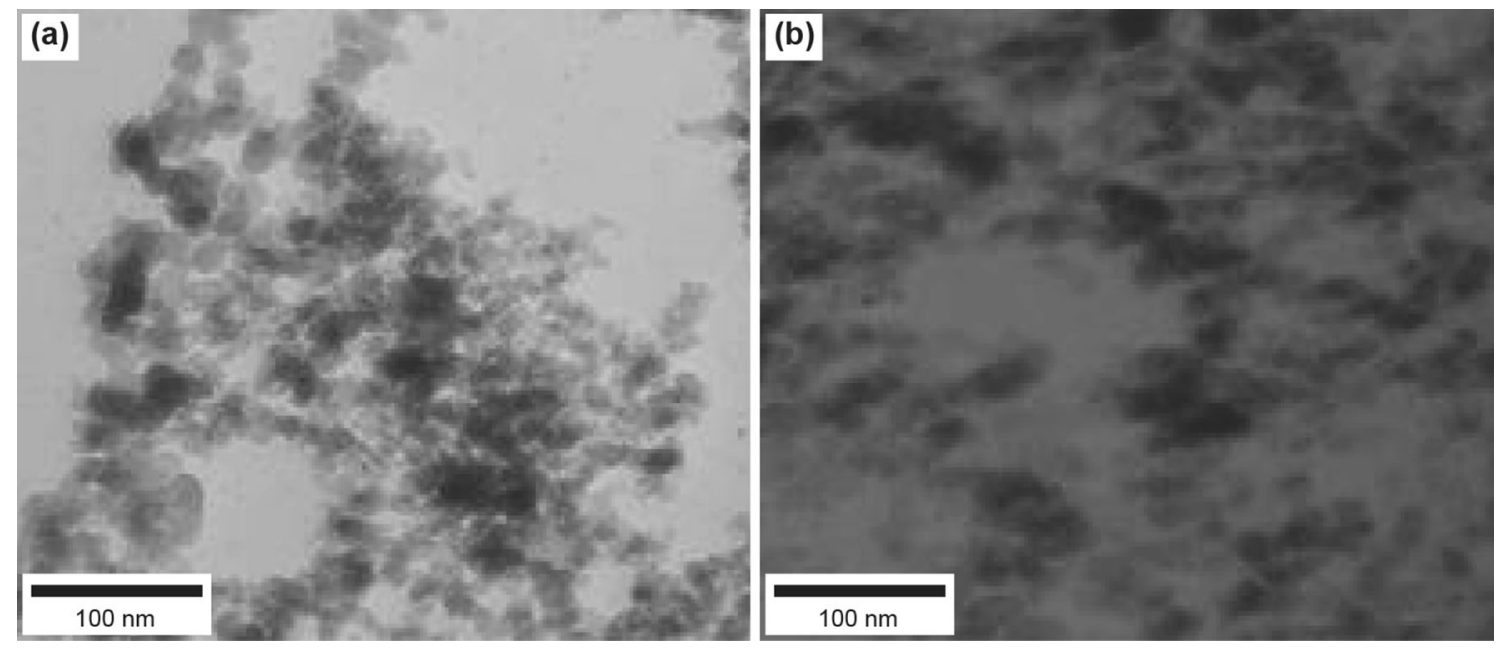

Fig. 1 Images of hydrophilic (a) and hydrophobic (b) silica nanoparticles observed with a TEM

Table 1 Characteristics of the utilized core sample

\begin{tabular}{llllllll}
\hline $\begin{array}{l}\text { Core } \\
\text { name }\end{array}$ & $\begin{array}{l}\text { Length, } \\
\mathrm{cm}\end{array}$ & $\begin{array}{l}\text { Average diameter, } \\
\mathrm{cm}\end{array}$ & $\begin{array}{l}\text { Area, } \\
\mathrm{cm}^{2}\end{array}$ & $\begin{array}{l}\text { Bulk volume, } \\
\mathrm{cm}^{3}\end{array}$ & $\begin{array}{l}\text { Pore volume }\left(S_{\mathrm{w}}=1\right), \\
\mathrm{cm}^{3}\end{array}$ & $\begin{array}{l}\text { Porosity, } \\
\%\end{array}$ & $\begin{array}{l}\text { Absolute permeability, } \\
\mathrm{mD}\end{array}$ \\
\hline $\mathrm{AB}$ & 8.51 & 3.8 & 11.40 & 97.1 & 13.7 & 14.1 & 1.98 \\
\hline
\end{tabular}



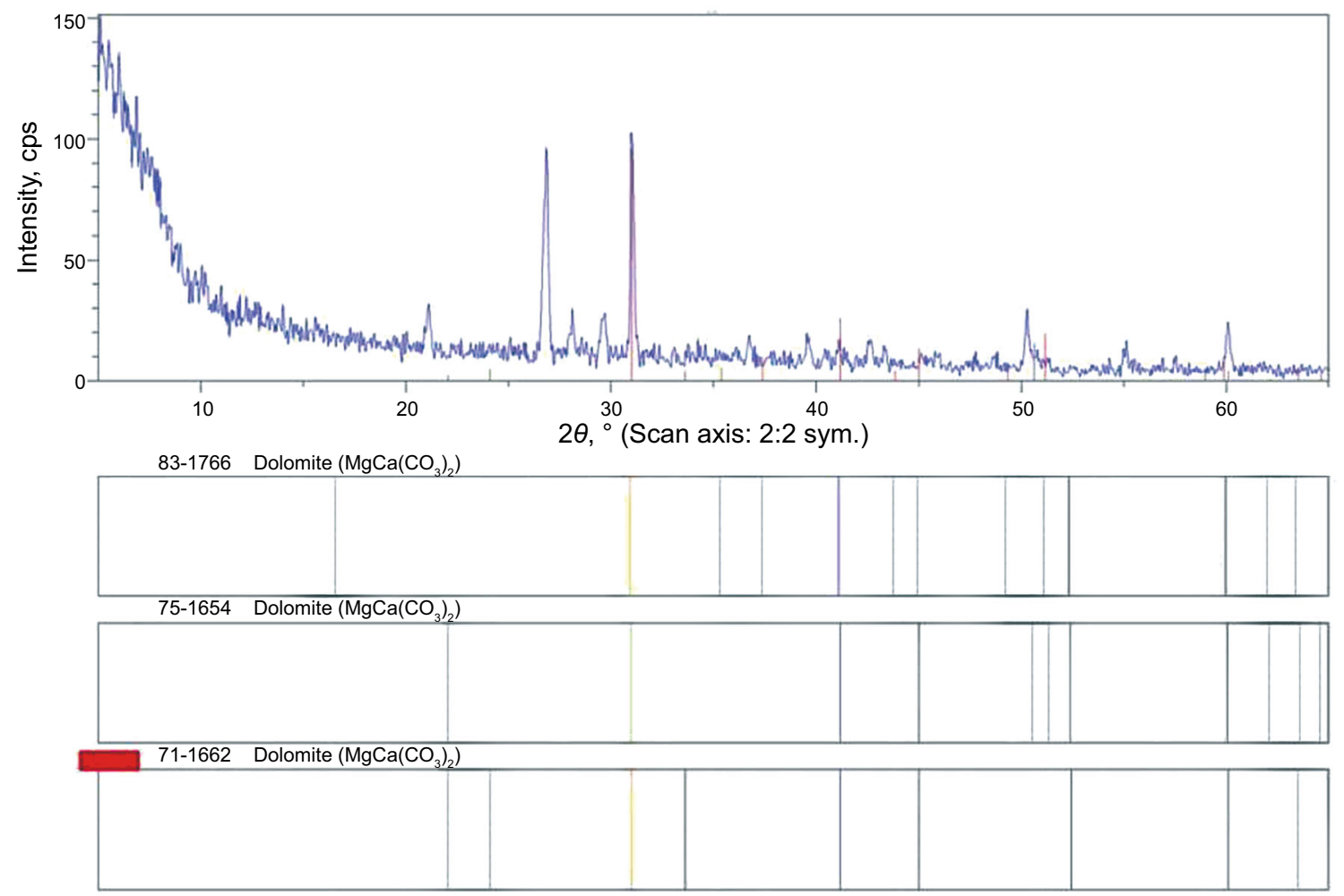

Fig. 2 X-ray diffraction (XRD) of the crushed rock samples

predominately dolomite. (As noted in the text, the major phase in the core sample is dolomite; however, it may contain some quartz. This is because the core is a real core sample, and it does not have a pure lithology.)

\subsection{Oil sample}

Crude oil used was taken from a light oil field located in the northern Persian Gulf. The properties of the crude oil sample are presented in Table 2 (Ahmadi and Shadizadeh 2013b).

\subsection{Determination of critical micelle concentration (CMC)}

Various methods were used to estimate the CMC of the surfactant in the aqueous solution based on different intrinsic characteristics of surface active agents, such as surface tension, interfacial tension, thermal conductivity, and electrical conductivity. Based on the high electrical conductance of the introduced surfactant in aqueous solutions, the electrical conductivity measurement was selected as a robust and precise method to determine the micellization behavior of the introduced surfactant with and without nanoparticles in aqueous solutions. To achieve the goals of this research, various concentrations of the
Table 2 Properties of crude oil used (after Ahmadi and Shadizadeh 2013b)

\begin{tabular}{ll}
\hline Property & Value \\
\hline Component, mol\% & \\
$\mathrm{H}_{2} \mathrm{~S}$ & 0 \\
$\mathrm{CO}_{2}$ & 0 \\
$\mathrm{~N}_{2}$ & 0 \\
$\mathrm{C}_{1}$ & 0 \\
$\mathrm{C}_{2}$ & 0.13 \\
$\mathrm{C}_{3}$ & 0.25 \\
$i$-C & \\
$n$-C & 0.73 \\
$i$-C & 1.23 \\
$n$-C & 1.38 \\
$\mathrm{C}_{6+}$ & 3.56 \\
Molecular weight of $\mathrm{C}_{6+}$ & 92.72 \\
Specific gravity of $\mathrm{C}_{6+}$ & 203.24 \\
\hline
\end{tabular}

introduced surfactant were considered ranging from 500 to $5000 \mathrm{ppm}$, and a plot of electrical conductance versus surfactant concentration for each nanoparticle concentration was generated. It should be noted that a conductivity detector from Crison Company (EC-GLP $31^{+}$) was used in experiments (Salari et al. 2011; Ahmadi and Shadizadeh 


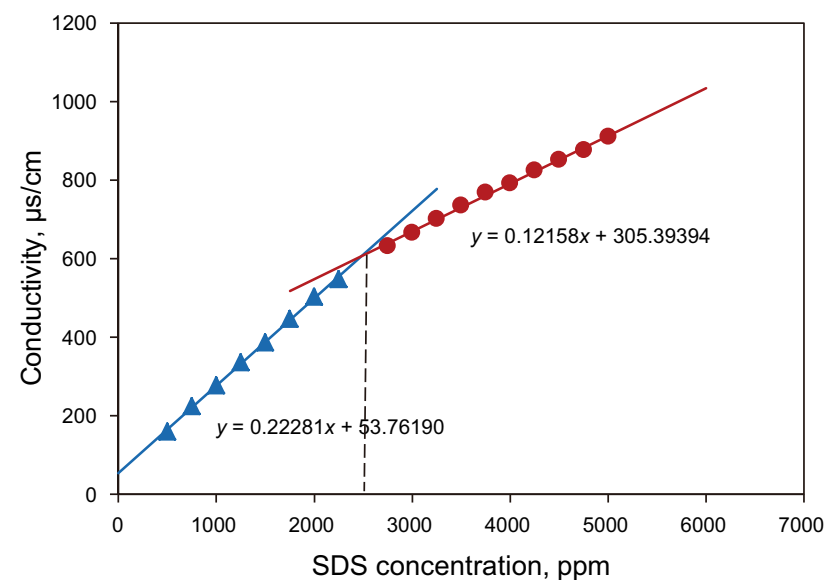

Fig. 3 Conductivity of SDS solutions versus corresponding surfactant concentration

2012, 2013c, 2015; Zendehboudi et al. 2013). The electrical conductivity trend of surfactant solutions at various concentrations without nanoparticles is illustrated in Fig. 3.

\subsection{Core displacement experiments}

To assess the performance of the chemical agents (surfactant, nanoparticle/surfactant) in enhanced oil recovery under reservoir conditions, a comprehensive series of core displacement experiments were carried out under high pressure and high temperature (HPHT). As shown in Fig. 4, the implemented setup consisted of two transfer vessels_-including one nanofluid and one oil-and a core holder mounted in a temperature-controlled air bath, which also enclosed an HPLC constant rate pump for high pressure injection of nanofluid or water. Also, to maintain the pressure of the system at the output of the core, a backpressure regulator (BPR) was installed. A differential pressure transducer (DPT) was used to measure the pressure drop across the core. Before each displacement experiment, the core sample was initially saturated with brine $(15,000 \mathrm{ppm} \mathrm{NaCl})$ and then flooded with oil at a low flow rate $(0.5 \mathrm{~mL} / \mathrm{h})$ until connate water saturation was reached under reservoir conditions. All core displacement tests were launched with the samples saturated with oil and connate water saturation, followed by the enhanced oil recovery (EOR) process. In each test, effluent fluids were collected for analysis. The displacement experiments were performed on several carbonate rocks which were water wet, $8.5 \mathrm{~cm}$ in length, and $3.8 \mathrm{~cm}$ in diameter. The scaling method proposed by Rapoport and Leas (1953) was carried out to cancel the dependency of oil recovery on the fluid injection rate and the core length. The mentioned scaling criterion is expressed by the following equation (Rapoport and Leas 1953; Kulkarni and Rao 2004; Mcelfresh et al. 2012; Ahmadi and Shadizadeh 2013b):

$L V \mu \geq 1$

where $L$ represents the core length, $\mathrm{cm} ; \mu$ stands for the viscosity of the displacing phase, $\mathrm{cP}$; and $V$ denotes the fluid velocity, cm/min (Rapoport and Leas 1953; Kulkarni and Rao 2004; Mcelfresh et al. 2012; Ahmadi and Shadizadeh 2013b).

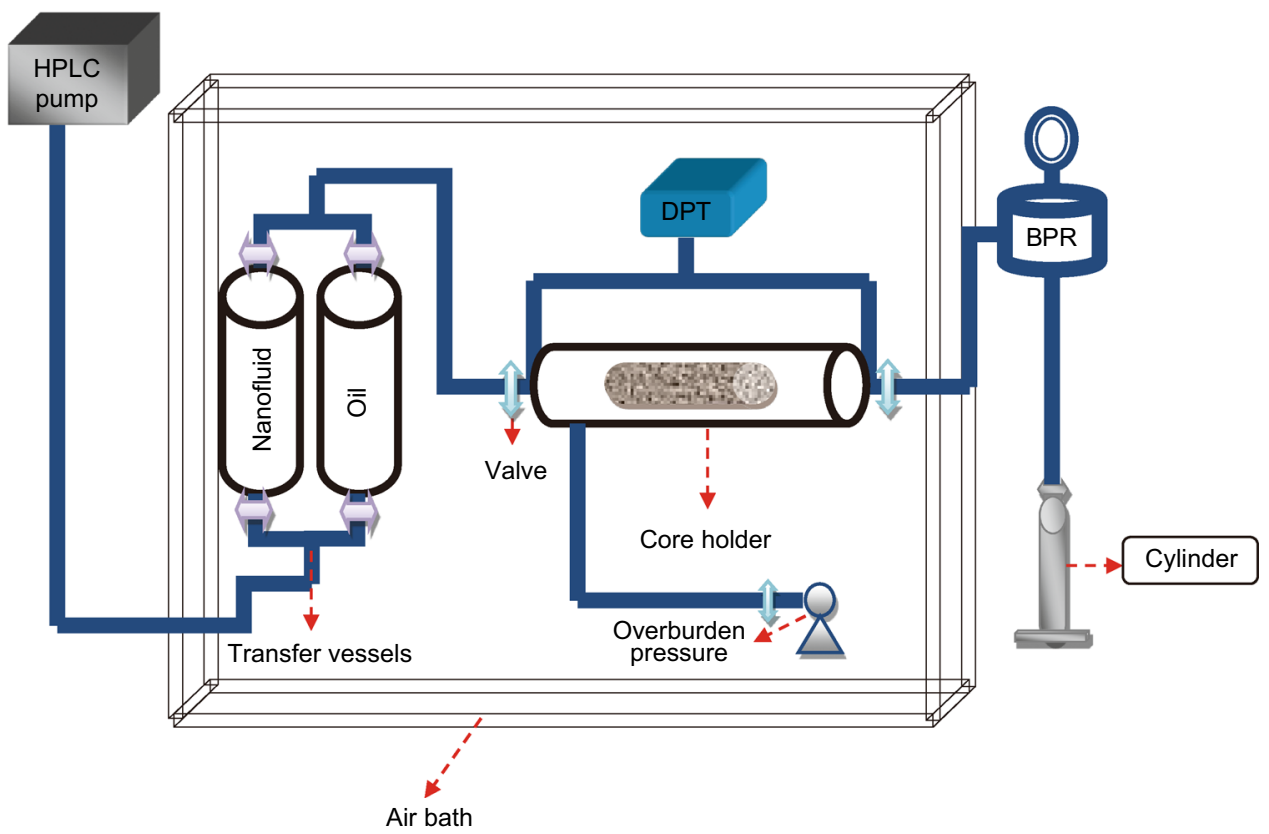

Fig. 4 Schematic picture of the core displacement apparatus 


\subsection{Adsorption experiment}

According to the procedure of adsorption experiments reported by Ahmadi and his colleagues (Ahmadi and Shadizadeh 2012, 2013c, 2015; Zendehboudi et al. 2013) and Salari et al. (2011), the depletion solution or batch tests were conducted to indicate adsorption behavior of the ionic surfactant on the carbonate surface in the presence of silica nanoparticles. Two crucial points of the proposed adsorption experiments are the adsorption equilibrium time and the ratio of the solid and aqueous phases. Before explaining the details of the adsorption experiments, it is worth mentioning that the experiments were conducted at $25{ }^{\circ} \mathrm{C}$ and atmosphere pressure. It should be mentioned here that to determine the amount of adsorption loss of the addressed ionic surfactant onto the reservoir rock samples, a batch test was used. Due to this fact, the weight of the crushed rock samples and the volume of the aqueous solution with different surfactant concentrations should be consistent for all the adsorption experiments as illustrated in Ahmadi and Shadizadeh (2012, 2013a, c, 2015). Two more crucial points should be mentioned: First, the equilibrium time of adsorption was about $24 \mathrm{~h}$, so adsorption experiments were conducted for $24 \mathrm{~h}$. Second, the mass ratio of the surfactant solution to the crushed rock was 5:1. In addition, a wide range of surfactant concentrations, from 500 to $5000 \mathrm{ppm}$ of surfactant, were used. As noted previously, the conductivity of the aqueous solution was utilized to indicate the surfactant concentration before and after adsorption loss onto the rock surface. For more details about the procedure of conductivity measurement for adsorption experiments, the authors referred to Ahmadi and Shadizadeh (2012, 2013a, c, 2015). Finally, the magnitude of the surfactant loss onto the rock surface (in terms of mg surfactant/g of rock) was calculated from the following formulation (Salari et al. 2011; Ahmadi and Shadizadeh 2012, 2013c, 2015; Zendehboudi et al. 2013):

$\Gamma=\left(\left(C_{\mathrm{i}}-C_{\mathrm{e}}\right) \times M_{\mathrm{s}} / M_{\mathrm{c}}\right) / 1000$,

where $\Gamma$ stands for the adsorption density, $\mathrm{mg} / \mathrm{g} ; C_{\mathrm{i}}$ and $C_{\mathrm{e}}$ represent the initial and equilibrium SDS concentrations in the aqueous solution, respectively, $\mathrm{ppm} ; M_{\mathrm{s}}$ denotes the mass of the solution, g; and $M_{\mathrm{c}}$ represents the mass of the carbonate rock sample, $\mathrm{g}$.

\section{Results and discussion}

\subsection{Adsorption experiments}

The CMC of SDS was determined by measuring the electrical conductivity of the solution, which was also used by Ahmadi and his coworkers (Salari et al. 2011; Ahmadi and Shadizadeh 2012, 2013c, 2015; Zendehboudi et al.

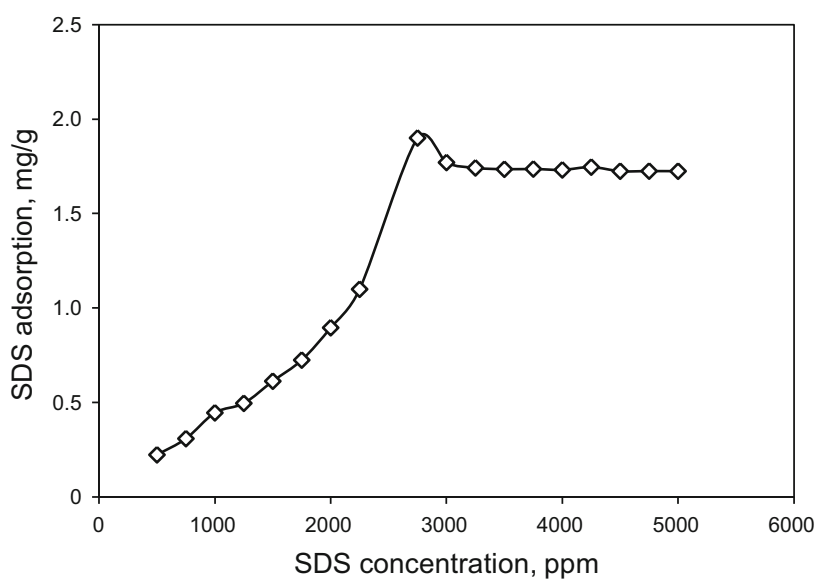

Fig. 5 Adsorption isotherm of SDS onto the crushed carbonate sample

2013). The CMC of SDS was 2485 ppm. The fate or loss of the surfactant in terms of $\mathrm{mg} / \mathrm{g}$ was measured in the aqueous and solid phases of an initial surfactant concentration from 500 to $5000 \mathrm{ppm}$ and a ratio of aqueous solution to solid of 5:1. Due to the achieved results of adsorption experiments under the mentioned conditions, the adsorption of SDS on the carbonate rock surface was different for the concentrations below and above the CMC.

As demonstrated in Fig. 5, by approaching the adsorption density of $1.90 \mathrm{mg} / \mathrm{g}$ at $2750 \mathrm{ppm}$ of the SDS concentration, adsorption reached equilibrium (constant value). In other words, increasing the SDS concentration that is lower than or equal to the CMC of SDS caused the amount of adsorption loss to follow linear behavior; however, the adsorption loss above a concentration of $2750 \mathrm{ppm}$ of SDS did not change significantly. The main reason for this phenomenon which can be explained by the number of SDS monomers does not change and remains constant after reaching the $\mathrm{CMC}$ value. On the other hand, when the SDS concentration is lower than the $\mathrm{CMC}$ value, the number of monomers is not a constant and increases with the SDS concentration. In this regard, increasing the SDS concentration, when it is lower than the $\mathrm{CMC}$ value, increases the adsorption density. So the maximum adsorption loss of SDS on the surface of crushed carbonate sample was about $1.90 \mathrm{mg} / \mathrm{g}$. It was found that the adsorption loss below or near the CMC value in the system is a function of the SDS concentration. Figure 6 shows the effect of hydrophilic silica nanoparticles on the adsorption of SDS on the crushed carbonate sample at different SDS concentrations. As shown in Fig. 6, more reduction was observed in the adsorption loss of SDS on the crushed carbonate sample when increasing the concentration of silica nanoparticles in aqueous solutions. This reduction is caused by the increasing concentration of hydroxyl groups, which exist in aqueous solutions and can create hydrogen bonds with the tail of the surfactant and an electrostatic bond with the positively 


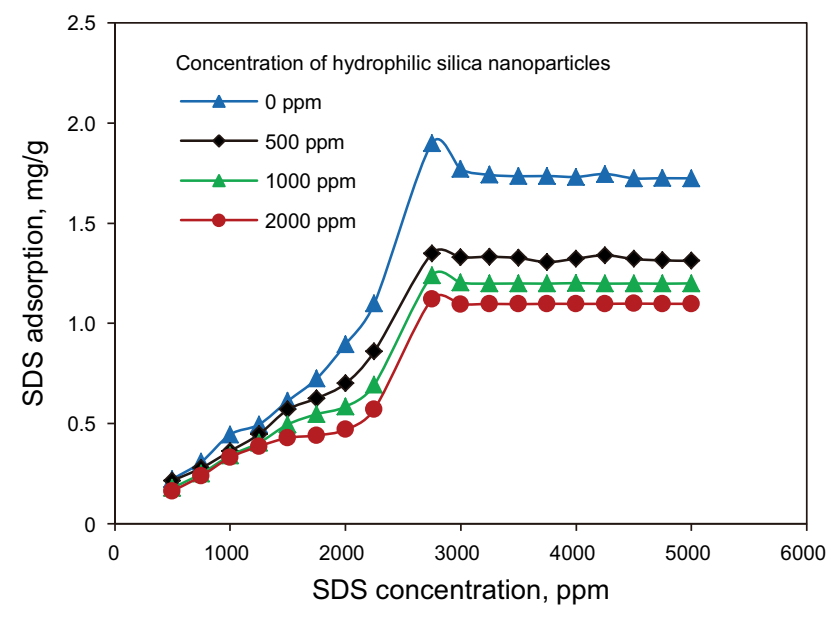

Fig. 6 Comparison of adsorption isotherms at different concentrations of hydrophilic silica nanoparticles

charged rock surface. Also another reason for the reduction is the adsorption of some silica nanoparticles on the crushed carbonate sample from the aqueous solution, but that is unfavorable for us because of the loss of silica nanoparticles from the solution. Figure 6 shows a comparison of the SDS adsorption efficiency at different concentrations of hydrophilic silica nanoparticles. As shown in Fig. 6, the effective concentration of hydrophilic silica nanoparticles was $2000 \mathrm{ppm}$, which could reduce the maximum value of the adsorption density from 1.90 to $1.12 \mathrm{mg} / \mathrm{g}$. Figure 7 depicts the effect of hydrophobic silica nanoparticles on the adsorption loss of SDS on the crushed carbonate samples at different SDS concentrations. As illustrated in Fig. 7, more reduction was observed in adsorption of SDS on the crushed carbonate sample when increasing the concentration of hydrophobic silica nanoparticles in the aqueous solution, but the magnitude of reduction was lower than the hydrophilic silica nanoparticles, owing to a smaller number of hydroxyl groups in hydrophobic silica nanoparticles. Due to this fact, the hydrophobic silica nanoparticles were observed to be less

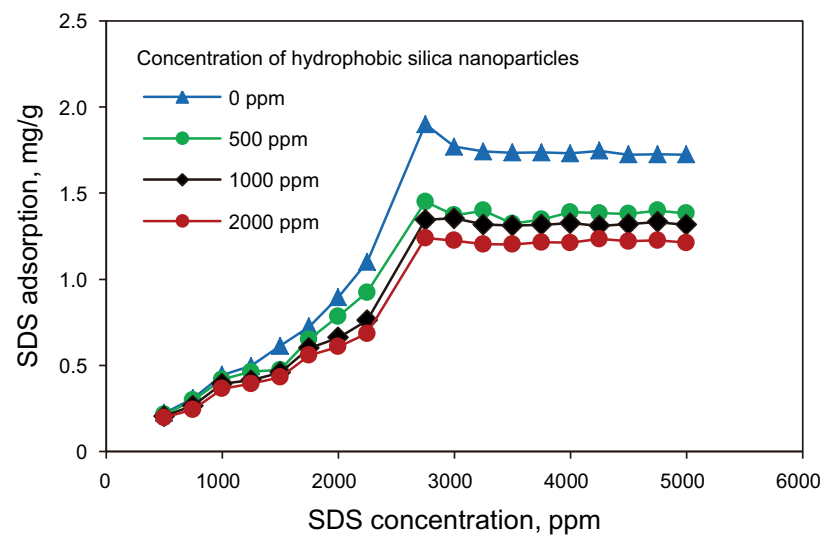

Fig. 7 Comparison of adsorption isotherms at different concentrations of hydrophobic silica nanoparticles effective in inhibiting adsorption loss of SDS onto the surface of crushed carbonate samples. As depicted in Fig. 7, increasing the silica nanoparticle concentration would reduce the losses of SDS onto reservoir rock samples. $2000 \mathrm{ppm}$ of silica nanoparticles could reduce the maximum value of adsorption loss from 1.90 to $1.24 \mathrm{mg} / \mathrm{g}$.
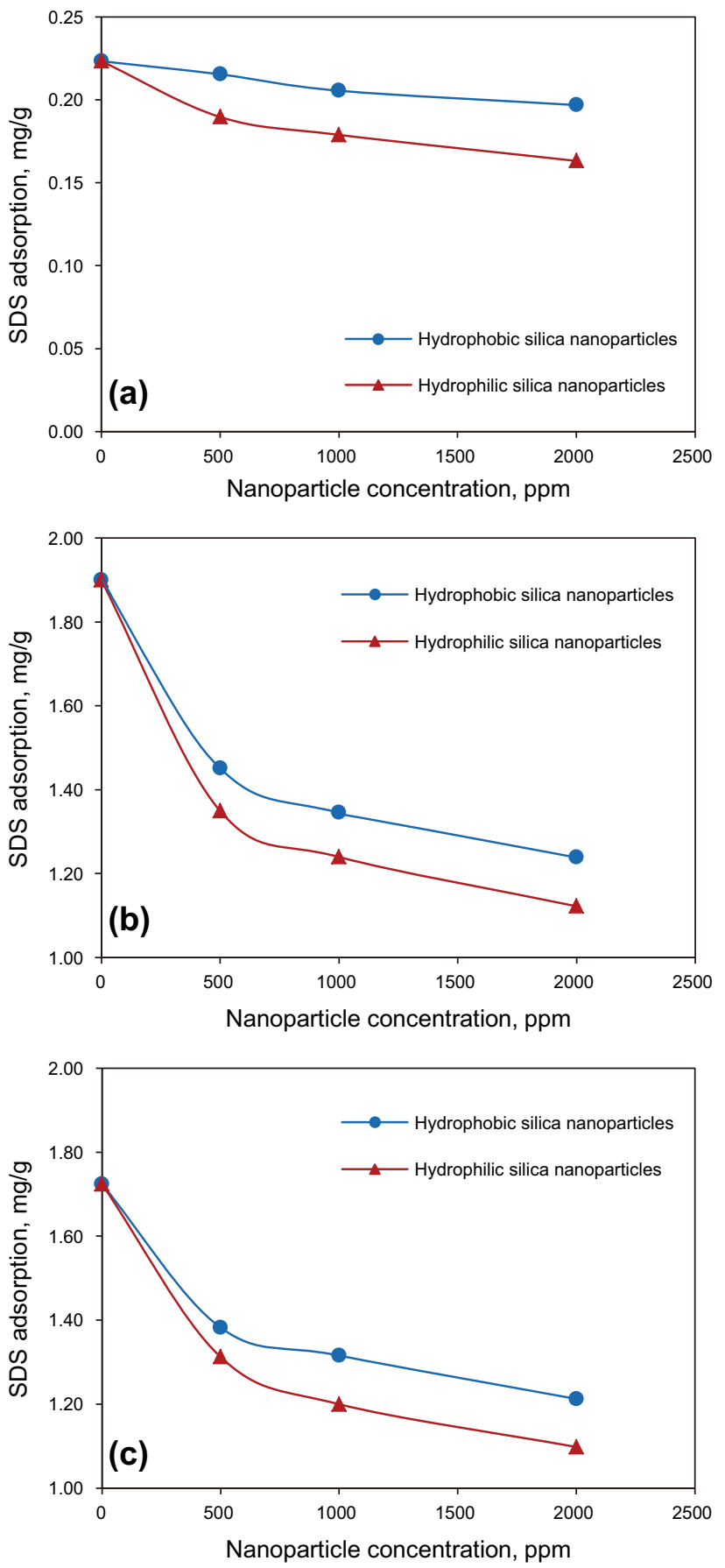

Fig. 8 Effects of hydrophilic and hydrophobic silica nanoparticles on the adsorption of SDS onto carbonate rock samples. a SDS concentration $C_{\mathrm{i}}=500 \mathrm{ppm}$ (lower than the CMC). b SDS concentration $C_{\mathrm{i}}=2750 \mathrm{ppm}$ (near the CMC). c SDS concentration $C_{\mathrm{i}}=5000 \mathrm{ppm}$ (above the CMC) 
(a)

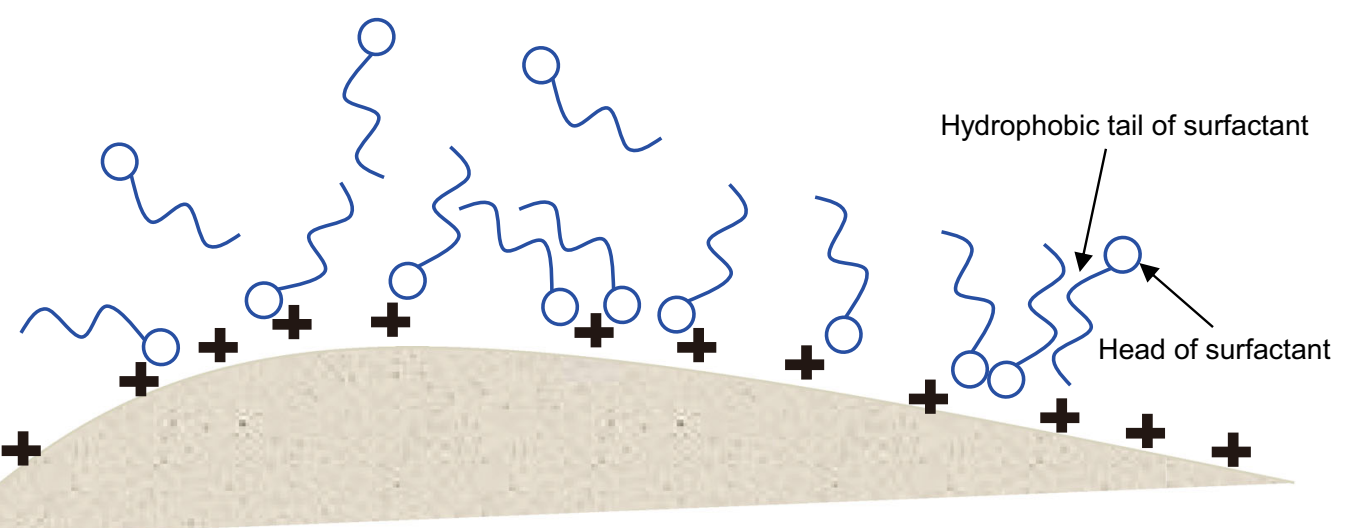

(b)

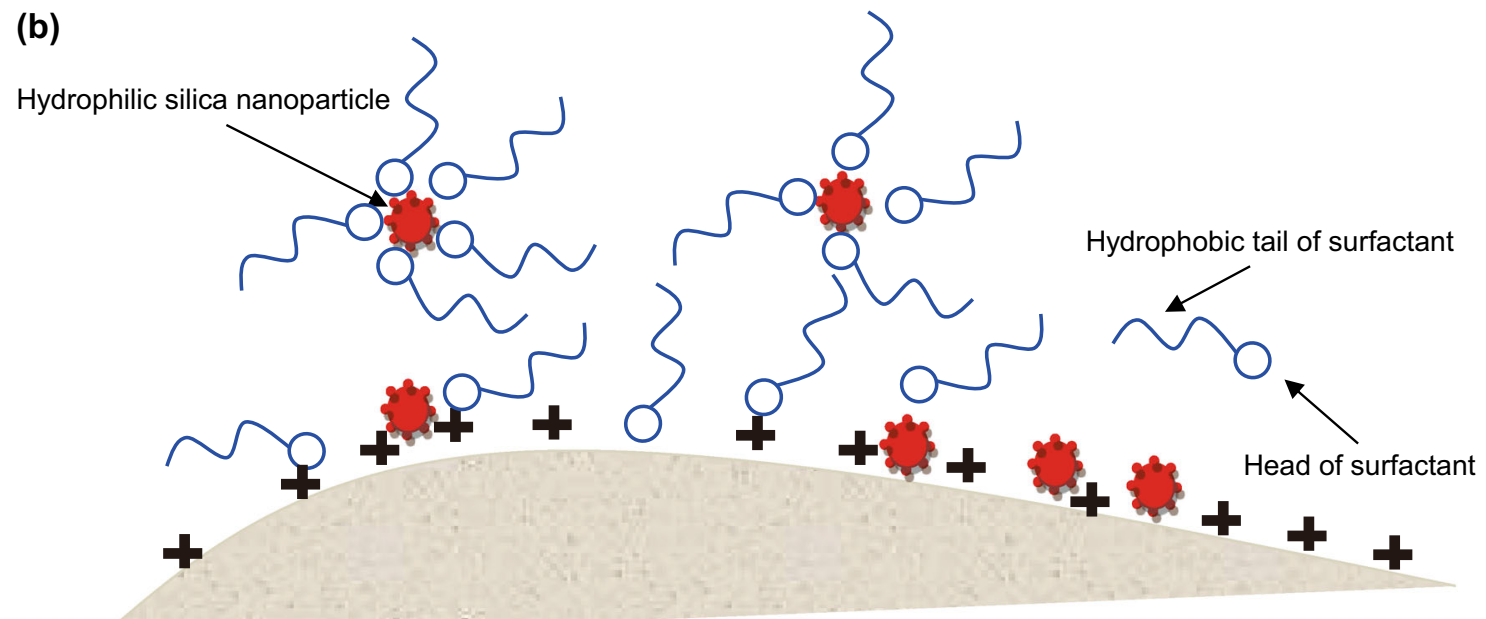

(c)

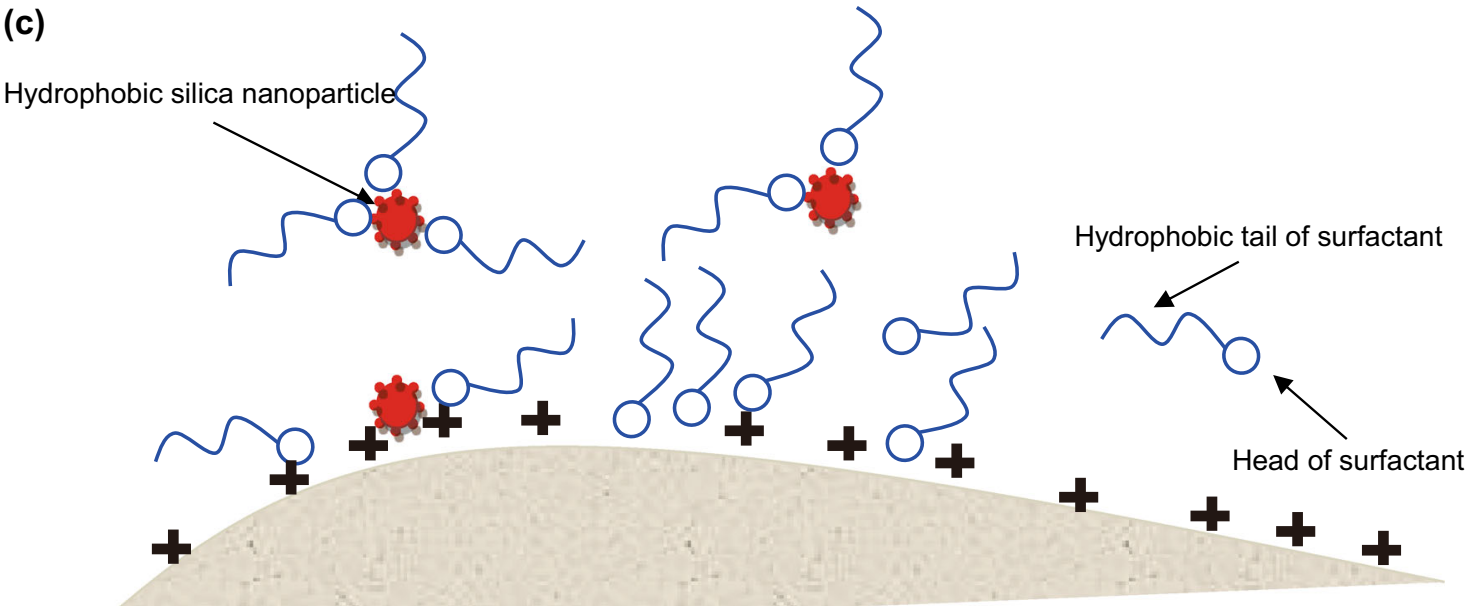

Fig. 9 Schematic of adsorption process of ionic surfactant. a Ionic surfactant only. b In the presence of hydrophilic silica nanoparticles. $\mathbf{c}$ In the presence of hydrophobic silica nanoparticles

Figure 8 compares the effects of hydrophilic and hydrophobic silica nanoparticles on the adsorption density of SDS at three levels of SDS concentration in the aqueous solution. When the SDS concentration (500 ppm) was lower than the CMC of SDS, the adsorption density decreases slightly with increasing concentration of silica nanoparticles (Fig. 8a). However, when the SDS concentration was near and above the CMC of SDS, the adsorption 
density decreases significantly with the increasing concentration of silica nanoparticles (Fig. 8b, c).

To better understand the adsorption mechanism of the ionic surfactant onto the carbonate rock surface, schematics of the adsorption of the surfactant alone and the surfactant in the presence of hydrophilic and hydrophobic silica nanoparticles are depicted in Fig. 9. As shown in Fig. 9a, the main mechanism of the surfactant adsorption onto the positively charged surface is electrostatic bonding between the negatively charged head of the surfactant and the positively charged surface. As mentioned previously, two main mechanisms exist to inhibit the surfactant loss onto positively charged carbonate rock samples. The first one is hydrogen bonding between hydroxyl groups of the silica nanoparticles and the tail of the ionic surfactant; the second is adsorption of the silica nanoparticles onto the carbonate rock surface due to a high magnitude of negative charges. In other words, silica nanoparticles were sacrificed to avoid adsorption loss of the surfactant at very low concentrations. These are depicted graphically in Fig. 9b, c.

\subsection{Effect of silica nanoparticles on CMC}

The changes in CMC that occur with increasing concentrations of hydrophobic and hydrophilic silica nanoparticles are depicted in Fig. 10. As mentioned earlier in the CMC determination section, a turning point in the plot of electrical conductivity against surfactant concentration represents the CMC of the surfactant. However, it seems that the hydrophobic and hydrophilic silica nanoparticles influenced the surfactant micellization properties, particularly its CMC. As can be seen in Fig. 10, the coexistence of SDS and hydrophilic silica nanoparticles (AEROSIL ${ }^{\circledR} 200$ ) in a solution led to a CMC value lower than the one for just the ionic surfactant system. Figure 10 demonstrates the $\mathrm{CMCs}$ of different systems considered in this study, and the presence of both nanoparticles resulted in surfactant molecules aggregating into micelles at lower concentrations. This phenomenon is more severe for higher nanoparticle concentrations.

The observed phenomenon may be related to the surfactant-nanoparticle interactions. Ignoring the small amount of surfactant adsorption on the surface of nanoparticles, the similar negative electrical charge on the surfactant head groups and the surface of nanoparticles results in an electrostatic repulsion between surfactant molecules toward each other, prompting the micellization process. Moreover, the hydrophilic nanoparticles make the bulk solution unfavorable for hydrophobic surfactant tails and increase their affinity to form micelles. Obviously, in such a situation, micelle aggregates form at lower concentrations, and the CMC is reduced. When the concentration of nanoparticles increases, the repulsion forces

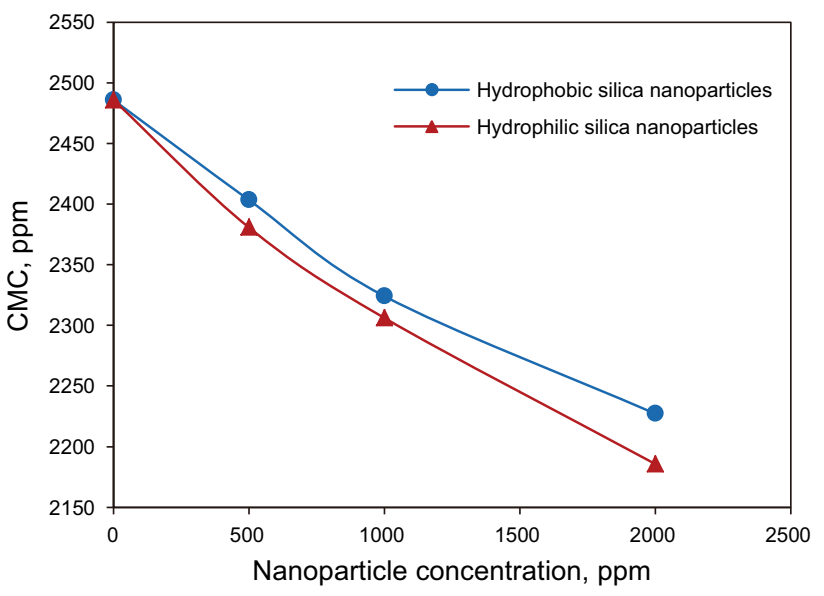

Fig. 10 Effect of silica nanoparticles on the CMC of SDS

become stronger (due to the larger number of nanoparticles). Also, the bulk solution becomes more hydrophilic. As a result, micellization occurs even at lower concentrations. Another important point that may be inferred from Fig. 10 is that the reduction in the CMC is more dramatic for hydrophilic silica nanoparticles. As mentioned earlier, the presence of these nanoparticles intensifies the hydrophilic characteristics of the solvent. In aqueous solutions, the greater dissimilarity between the hydrophobic chain of the surfactant and silica nanoparticles leads to higher aggregation. Consequently, a sharper decrease in the CMC value is observed than with the slightly hydrophobic nanoparticles (AEROSIL ${ }^{\circledR}$ 816). The previous discussions are illustrated in Fig. 11.

\subsection{Core displacement results}

The induced effects of the nanoparticles on the ultimate oil recovery and performance of the ionic surfactant in porous media were examined. Figure 12 demonstrates the ultimate oil recovery in terms of $\%$ original oil in place (\% OOIP) versus volume of the fluid injected into the porous media for four different water-oil systems. As depicted in Fig. 12, the oil recovery was $51.1 \%$ OOIP with water injection. Also, as demonstrated in Fig. 12, adding 5000 ppm of SDS to the aqueous phase resulted in more oil production and the recovery factor was about $78.8 \%$ OOIP. This may be explained by the reduction in the interfacial tension between two immiscible fluids (water and oil). Moreover, the addition of hydrophobic and hydrophilic silica nanoparticles could improve the sweep efficiency of SDS, and more oil was recovered from the porous media due to inhibition of adsorption loss of the surfactant, but the magnitude of the ultimate oil recovery highly depended on the hydrophobicity of silica nanoparticles. For better understanding, it is worth mentioning that the hydrophobic 


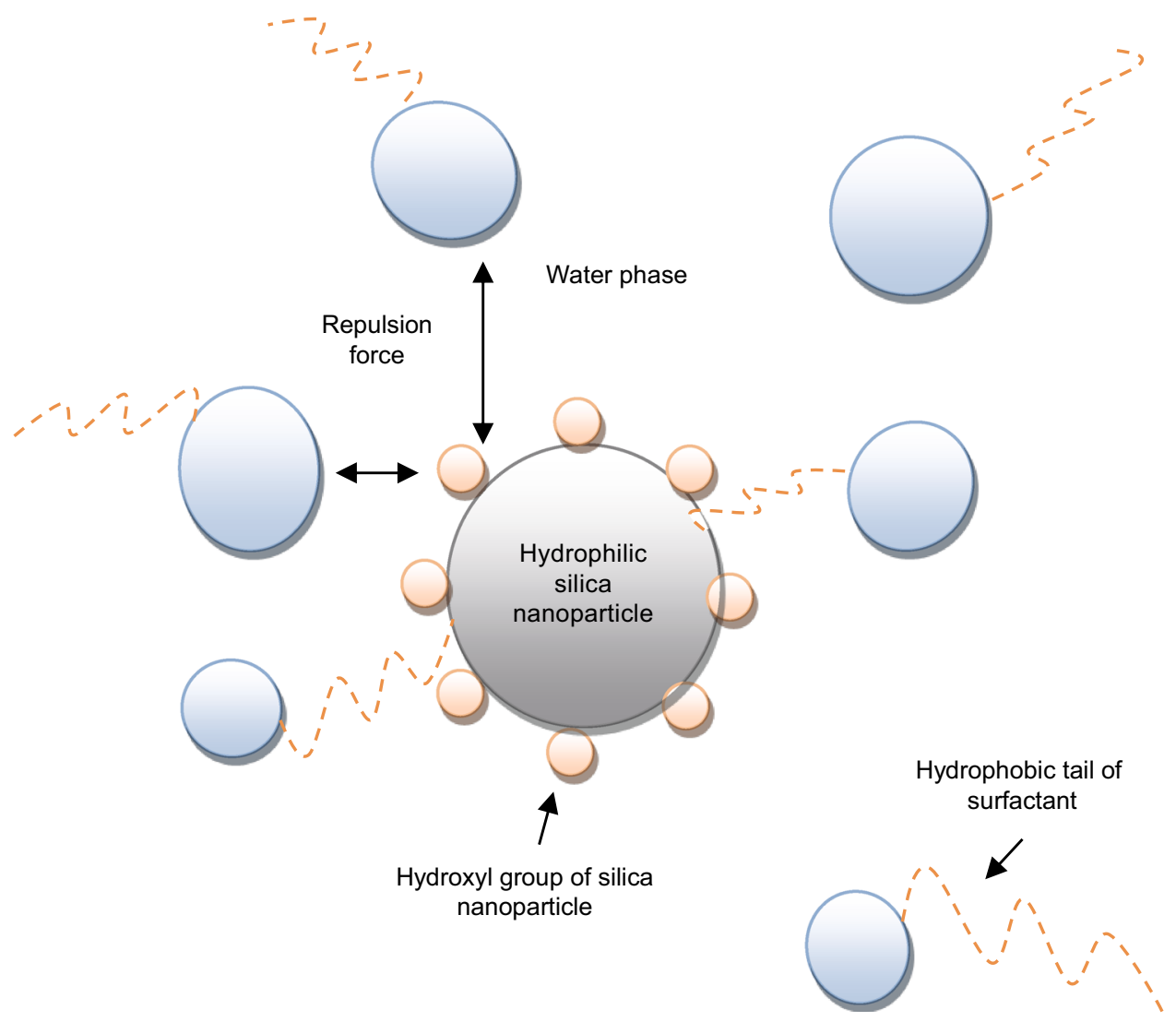

Fig. 11 Schematic of aggregation of silica nanoparticles and SDS

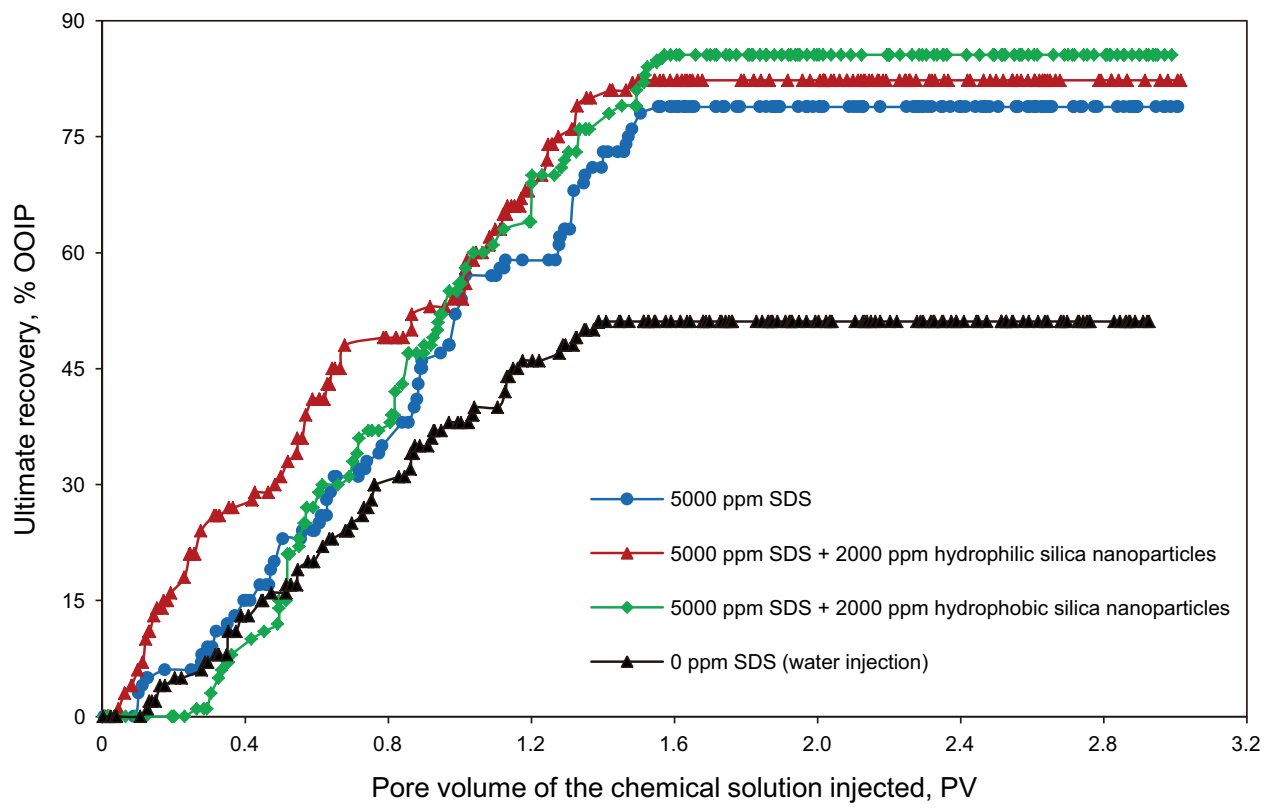

Fig. 12 Comparison of ultimate oil recovery for four systems including water, SDS solution only, and combinations of the SDS solution and silica nanoparticles 
silica nanoparticles may reduce the interfacial tension between oil and water phases, but the effect of hydrophilic silica nanoparticles is the reverse. According to the noted facts, the ultimate oil recoveries were 82.3 and $85.6 \%$ OOIP for the hydrophilic and hydrophobic silica nanoparticles, respectively.

\section{Conclusions}

1. The addition of both hydrophilic and hydrophobic silica nanoparticles could reduce adsorption loss of the ionic surfactant.

2. The hydrophilic silica nanoparticles could be more effective than the hydrophobic ones in reducing adsorption onto carbonate samples, because there are more hydroxyl groups in hydrophilic silica nanoparticles than in hydrophobic silica particles. Owing to this fact, more hydrogen bonds exist between hydroxyl groups and the tail of the ionic surfactant, while more electrostatic bonds are formed between hydroxyl groups of silica nanoparticles and positively charged rock surfaces are also observed.

3. When the SDS concentration was lower than the CMC of SDS, the adsorption density decreases slightly with the increasing concentration of silica nanoparticles. However, when the SDS concentration was near and above the CMC of SDS, the adsorption density decreases significantly with the increasing concentration of silica nanoparticles.

4. The addition of silica nanoparticles to the surfactant solution resulted in decreasing the $\mathrm{CMC}$ of the ionic surfactant. However, the magnitude of the CMC was noticeably dependent on the hydroxyl group and the magnitude of the negative charges on the silica nanoparticle surface. In other words, the hydrophilic silica nanoparticles could reduce the CMC value more than the hydrophobic silica nanoparticles in the aqueous solution.

5. The addition of silica nanoparticles could improve the sweep efficiency of the ionic surfactant. However, the magnitude of the additional oil recovery was highly dependent on the wettability of the silica nanoparticles. For hydrophobic silica nanoparticles, the reduction in interfacial tension and the inhibition of adsorption loss were two factors in favor, but these phenomena were different for hydrophilic silica nanoparticles. Hydrophilic silica nanoparticles could inhibit adsorption loss of the surfactant; however, it increased the interfacial tension between oil and water and hence did not improve the oil recovery as much as the hydrophobic nanoparticles.
Open Access This article is distributed under the terms of the Creative Commons Attribution 4.0 International License (http://crea tivecommons.org/licenses/by/4.0/), which permits unrestricted use, distribution, and reproduction in any medium, provided you give appropriate credit to the original author(s) and the source, provide a link to the Creative Commons license, and indicate if changes were made.

\section{References}

Adkins SS, Gohil D, Dickson JL, Webber SE, Johnston KP. Water-incarbon dioxide emulsion stabilized with hydrophobic silica particles. Phys Chem Chem Phys. 2007;9(48):6333-43. doi:10. 1039/b711195a.

Ahmadi MA, Arabsahebi Y, Shadizadeh SR, Shokrollahzadeh Behbahani S. Preliminary evaluation of mulberry leaf-derived surfactant on interfacial tension in an oil-aqueous system: EOR application. Fuel. 2014;117(Part A):749-55. doi:10.1016/j.fuel. 2013.08.081.

Ahmadi MA, Shadizadeh SR. Adsorption of novel nonionic surfactant and particles mixture in carbonates: enhanced oil recovery implication. Energy Fuels. 2012;26(8):4655-63. doi:10.1021/ ef300154h.

Ahmadi MA, Shadizadeh SR. Experimental investigation of adsorption of a new nonionic surfactant on carbonate minerals. Fuel. 2013a;104:462-7. doi:10.1016/j.fuel.2012.07.039.

Ahmadi MA, Shadizadeh SR. Implementation of high performance surfactant for enhanced oil recovery from carbonate reservoir. J Pet Sci Eng. 2013b;110:66-73. doi:10.1016/j.petrol.2013.07. 007.

Ahmadi MA, Shadizadeh SR. Induced effect of adding nano silica on adsorption of new surfactant onto sandstone rock: experimental and theoretical study. J Pet Sci Eng. 2013c;112:239-47. doi:10. 1016/j.petrol.2013.11.010.

Ahmadi MA, Shadizadeh SR. Experimental and theoretical study of a new plant derived surfactant adsorption on quartz surface: kinetic and isotherm. J Dispers Sci Technol. 2015;36(3):441-52. doi:10.1080/01932691.2013.860035.

Al-Anssari S, Lebedev M, Wang S, Barifcani A, Iglauer S. Wettability alteration of oil-wet carbonate by silica nanofluid. J Colloid Interface Sci. 2016;461:435-42. doi:10.1016/j.jcis. 2015.09.051.

Dickson J, Johnston K, Binks B. Stabilization of carbon dioxide-inwater emulsions with silica nanoparticles. Langmuir. 2004;20(19):7976-83. doi:10.1021/la0488102.

Hendraningrat L, Engeset B, Suwarno S, Torsæter O. Improved oil recovery by nanofluids flooding: an experimental study. In: SPE Kuwait international petroleum conference and exhibition, 10-12 December, Kuwait City, Kuwait, 2012. doi:10.2118/ 163335-MS.

Hendraningrat L, Li S, Torsæter O. A coreflood investigation of nanofluid enhanced oil recovery. J Pet Sci Eng. 2013;111:128-38. doi:10.1016/j.petrol.2013.07.003.

$\mathrm{Ju} \mathrm{B}$, Fan T. Experimental study and mathematical model of nanoparticle transport in porous media. Powder Technol. 2009;195(2):192-202. doi:10.1016/j.powtec.

Kanj MY, Al-Yousif Z, Funk J. Nano fluid core flood experiment in the ARAB-D. In: SPE Saudi Arabia section technical symposium and exhibition, 9-11 May, Aikhobar, Saudi Arabia, 2009. doi:10.2118/126161-MS

Kong X, Ohadi MM. Application of micro and nano technologies in the oil and gas industry: an overview of the recent progress. In: Abu Dhabi international petroleum exhibition \& conference, 1-4 November, Abu Dhabi, UAE, 2010. doi:10.2118/138241-MS. 
Kulkarni MM, Rao DN. Experimental investigation of various methods of tertiary gas injection. In: SPE annual technical conference and exhibition, 26-29 September, Houston, TX, 2004. doi:10.2118/90589-MS.

Le N, Pham DK, Le KH, Nguyen PT. Design and screening of synergistic blends of $\mathrm{SiO}_{2}$ nanoparticles and surfactants for enhanced oil recovery in high-temperature reservoirs. Adv Nat Sci. 2011;2(3):035013. doi:10.1088/2043-6262/2/3/035013.

Li S, Hendraningrat L, Torsæter O. Improved oil recovery by hydrophilic silica nanoparticles suspension: 2- phase flow experimental studies. In: International petroleum technology conference, 26-28 March, Beijing, China, 2013. doi:10.2523/ IPTC-16707-MS.

Mcelfresh P, Holcomb D, Ector D. Application of nanofluid technology to improve recovery in oil and gas wells. In: SPE international oilfield technology conference, 12-14 June, Noordwijk, The Netherlands, 2012. doi:10.2118/154827-MS.

Ogolo N, Olafuyi O, Onyekonwu M. Enhanced oil recovery using nanoparticles. In: SPE Saudi Arabia section technical symposium and exhibition, 8-11 April, Al-Khobar, Saudi Arabia, 2012. doi:10.2118/160847-MS.

Onyekonwu MO, Ogolo NA. Investigating the use of nanoparticles in enhancing oil recovery. In: Nigeria Annual international conference and exhibition, 31 July-7 August, Tinapa-Calabar, Nigeria, 2010.

Rapoport LA, Leas WJ. Properties of linear waterfloods. J Pet Technol. 1953;5(5):139-48. doi:10.2118/213-G.
Salari Z, Ahmadi MA, Kharrat R, Abbaszadeh Shahri A. Experimental studies of cationic surfactant adsorption onto carbonate rocks. Aust J Basic Appl Sci. 2011;5(12):808-13.

Shah RD. Application of nanoparticle saturated injectant gases for EOR of heavy oil. In: SPE annual technical conference and exhibition, 4-7 October, New Orleans, Louisiana, USA, 2009. doi:10.2118/129539-STU.

Skauge T, Spildo K, Skauge A. Nano-sized particles for EOR. In: SPE improved oil recovery symposium, 24-28 April, Tulsa, Oklahoma, USA, 2010. doi:10.2118/129933-MS.

Suleimanov B, Ismalov F, Veliyev E. Nano fluid for enhanced oil recovery. J Pet Sci Eng. 2011;78(2):431-7. doi:10.1016/j.petrol. 2011.06.014.

Zang L, Yuan J, Liang H, Le K. Energy from abandoned oil and gas reserves. In: SPE Asia Pacific oil and gas conference and exhibition, 20-22 October, Perth, Australia, 2008. doi:10.2118/ 115055-MS.

Zendehboudi S, Ahmadi MA, Rajabzadeh AR, Mahinpey N, Chatzis I. Experimental study on adsorption of a new surfactant onto carbonate reservoir samples-application to EOR. Can J Chem Eng. 2013;91(8):1439-49. doi:10.1002/cjce.21806.

Zhang T, Davidson A, Bryant SL, Huh C. Nanoparticle-stabilized emulsions for application in enhanced oil recovery. In: SPE improved oil recovery symposium, 24-28 April, Tulsa, Oklahoma, USA, 2010. doi:10.2118/129885-MS. 